146 The LanceT,] DR. WHITING : RECENT ADVANCES IN OUR KNOWLEDGE OF HEAR'T DISEASE."[JuLY20,1912.

\begin{tabular}{|c|c|c|c|c|c|c|c|c|c|c|}
\hline \multicolumn{11}{|c|}{$\begin{array}{c}\text { Case 21.-Female, aged 14. Scarlet Fever with Nasal } \\
\text { Diphtheria Infection. }\end{array}$} \\
\hline Date. & $\begin{array}{l}\text { 它 } \\
\text { i } \\
\dot{8} \\
\text { ฉ }\end{array}$ & 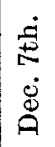 & Dec. 8th. & 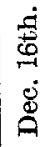 & Dec. 17th. & 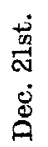 & 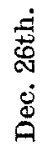 & 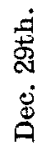 & 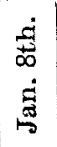 & 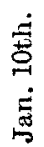 \\
\hline Nose $\quad \ldots \quad \ldots$ & + & + & $\left\{\begin{array}{c}0.5 \mathrm{mgm} . \\
\text { of } \\
\text { endotoxin }\end{array}\right.$ & + & $\begin{array}{c}1 \mathrm{mgm} . \\
\text { of } \\
\text { endotoxin }\end{array}$ & + & + & + & - & - \\
\hline
\end{tabular}

\title{
RECENT ADVANCES IN OUR KNOWLEDGE OF HEART DISEASE. ${ }^{1}$
}

By ARThUR J. WHITING, M.D. Edin., M.R.C.P. LoNd.,

LECTURER IN, AND DEAN OF, THE NORTH-EAST IONDON POSTGRADUATE COLLEGE; PHYSICIAN TO THE MOUNT VERNON HOSPITAL FOR CONSUMP'IION AND OTHER DISEASES OF THE CHEST; PHYSICIAN TO THE PRINCE OF WALES'S GENERAL HOSPI'AX, N.

IN responding this evening to your request to read a paper before your distinguished Medical Society, I intend to try to give a "bird's-eye view" of the newer cardiology, as it may be termed, and I shall be content if I can make clear some of its principal landmarks.

In the first place, let me try to answer the question,

\begin{tabular}{|c|c|c|c|c|c|c|c|}
\hline Date. & 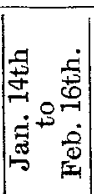 & Feb. 17th. & 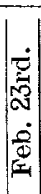 & Feb. 24th. & 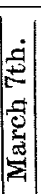 & March 8th. & 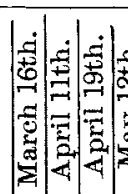 \\
\hline Nose... & $\begin{array}{l}+ \\
+\end{array}$ & $\left\{\begin{array}{c}0.5 \mathrm{mgmm} . \\
\text { of endo- } \\
\text { toxin. }\end{array}\right\}$ & $\begin{array}{l}+ \\
+\end{array}$ & $\left\{\begin{array}{c}1 \mathrm{mgm} . \\
\text { of endo- } \\
\text { toxin. }\end{array}\right\}$ & 0 & $\left\{\begin{array}{c}2.5 \mathrm{mgm} . \\
\text { of endo- } \\
\text { toxin. }\end{array}\right\}$ & $\left\{\begin{array}{l}-\begin{array}{l}-0 \\
+ \\
+\end{array} .\end{array}\right.$ \\
\hline
\end{tabular}

Case 23.-Male, aged 11. Scarlet Fever, with Chronic Diphtheria Infection of the Nose and Throat.

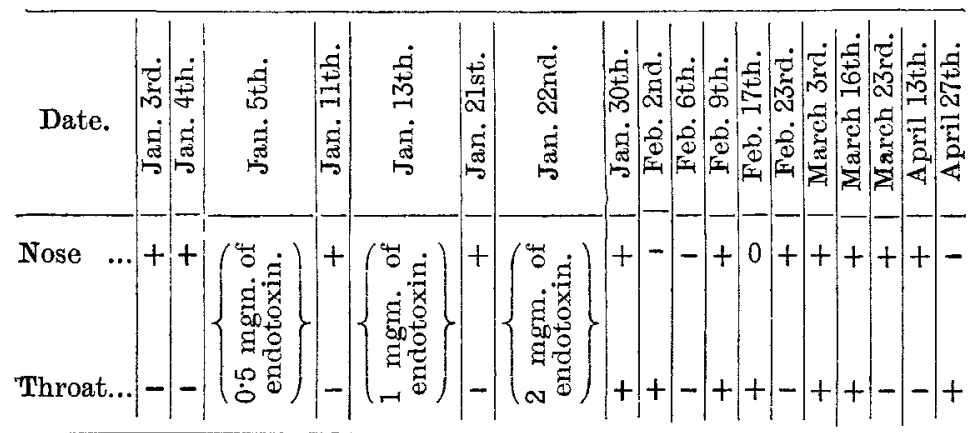

Case 24.-Male, aged 14. Chronic Diphtheria Infection of the Nose.

The condition did not yield to endotoxin, although the dosage was large, but the infection ceased almost immediately when a necrotic turbinate bone was removed on March 10th.

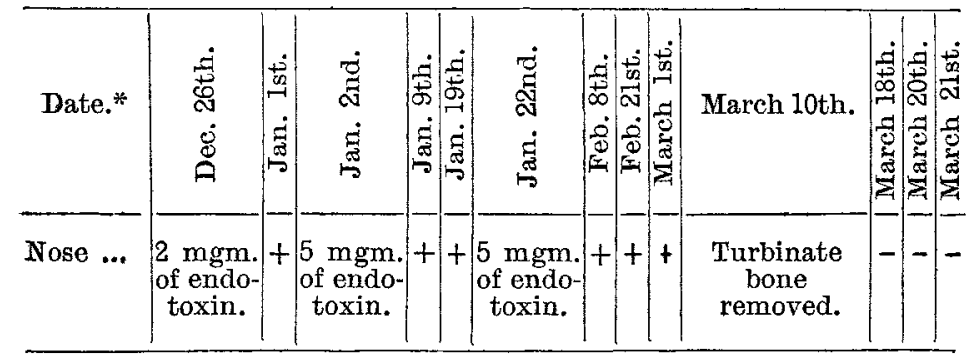

* Sept. 8th to Dec. 24th, +.

In conclusion, we wish to thank Dr. Dale, of the Wellcome Physiological Research Laboratories, who kindly allowed the diphtheria endotoxin to be prepared for us; and also Dr. Meredith Richards and Dr. M. B. Arnold, the medical officer of health of Croydon and superintendent of the Borough Fever Hospital, for permission to publish these cases.

The diphtheria endotoxin was prepared by growing a virulent B. diphtheriæ on serum or blood-agar in Roux bottles, collecting the growth, washing it two or three times in sterile physiological salt solution by centrifuging so as to remove any adherent toxin, grinding the bacterial mass by the Macfadyen method in the presence of intense cold, and filtration of the ground mass through a Berkefeld filter. The filtrate forms the endotoxin and is standardised by the addition of sterile salt solution so as to contain $2 \mathrm{mgm}$. or $5 \mathrm{mgm}$. per c.c. It was found by one of us (R. T. H.) that this endotoxin solution was harmless to guinea-pigs and that it possessed considerable protective power against injections of living B. diphtheriæ. ${ }^{1}$ One of us (A. T. N.) also injected himself with doses of $2 \mathrm{mgm}$. and $5 \mathrm{mgm}$. with the production only of the local reaction mentioned above.

What help has it been to us? I would say that it has made us more clearly to understand that heart murmurs due to deformities of the cardiac valves may be of little account, and that a murmurless heart may be a dangerousiy damaged heart. It is true that we knew or believed this before, but our idea, I suggest, is now more concrete and our belief more rational. The newer cardiology has demonstrated, in short, that the point of prime importance is how the heart is doing its work; if well, then, say we, let it murmur as much as it likes.

Further, it has enabled us to discriminate between the irregularities of the pulse which in regard to prognosis are trivial and those which are grave. Formerly we had a vague idea that some pulse irregularities were of no special significance and others were serious, but one could hardly say in any particular instance to which category it belonged or give any valid reason for thinking it either trivial or serious. And this and much more we are glad to recognise we owe in large measure to the clinical work of my distinguished colleague, Dr. James Mackenzie.

The root idea of this newer cardiology resulted from the work of Gaskell, to whom the origin of the myogenic theory -a theory which harmonises and explains many diverse facts-must be ascribed. According to that theory the transmission of the cardiac contractions from one chamber to another, auricles to ventricles, is not, as you are aware, a matter of impulses along nerve tracts, but of waves along muscle bundles. The theory, however, does not exclude the functional importance of nerve cells and nerve fibres, in which the heart itself is so rich, but according to it the nerve element is secondary in importance. Shortly stated, the theory, as you know, supposes that the fibres of the myocardium produce and accumulate in their interior a " stimulus substance" which, when in sufficient quantity or under sufficient tension, causes the contraction of the heart fibres; this property of the myocardium we speak of as "stimulus formation."

At this point, however, it is desirable to take into account two special and peculiar attributes of the heart muscle: one is that when it is stimulated, by however strong or however feeble a stimulus, it contracts to the fullest extent of which it is capable or not at all ; this has been called the "all or nothing" attribute. The second law is that during the heart's contraction the stimulus material is used up, and the muscle for an appreciable time is unable to contract in response to any stimulus, however strong; this gives rise to the "refractory period" of the cardiac cycle, and it corresponds in time with the phase of rest during which the stimulus substance is being reaccumulated. After the resting stage the second and third functions of the myocardium, "excitability" and "contractility" (whose names explain themselves) again become effective.

The fourth function is that of " conductivity," in virtue of which the contraction wave is transmitted from the contracting fibres to adjoining fibres, giving rise to the fully developed "contraction wave" which, starting from near the openings of the great veins into the right auricle-the representative of the sinus venosus of the lower animalssweeps through the auricles and ventricles to the apical region of the heart, to end in the contraction of the musculi papillares. Fifthly, the heart muscle, like the skeletal muscles, has the property of "tonicity," through which the fibres are in a state of slight permanent contraction, even when the muscle as a whole is relaxed.

2 Proceedings of the Royal Society, London, B, vol. Ixxxiv., 1911, p. 49. 
These, then, are the five physiological properties of heart muscle: (1) stimulus formation, (2) excitability, (3) contractility, (4) conductivity, and (5) tonicity; and, as we know, each may be the subject of pathological variation, either alone or in association with others.

In the primitive cardiac tube and in the heart of the lower vertebrates the wave of contraction passes from one end of the tube to the other and from one chamber to anothersinus venosus, auricle, ventricle, conus arteriosus-by actual structural continuity of muscle fibres, but not so in man or the higher vertebrates, for, as you know, there is a nonmuscular fibrous ring separating auricles from ventricles, breaking this continuity. Yet, as Stanley Kent and His, jun., were among the first to show, there is a medium of muscular continuity from auricle to ventricle-the auriculo-ventricular bundle, or bundle of His, or shortly "the bundle." This starts in a remnant of the primitive cardiac tube situated in the wall of the right auricle near the openings of the venæ cavæ-the "sino-auricular node." It passes as a narrow cord to the auriculo-ventricular junction and along the upper fibrous part of the interventricular septum, and then divides into two main branches, one going to the right ventricle and the other to the left, each eventually ramifying in the ventricular walls as the well-known Purkinje fibres.

During diastole, then, the stimulus substance accumulates in the fibres of the heart muscle, contraction starts at its most excitable part- the "sino-auricular node," or so-called "pace-maker" of the heart-and passes down the bundle of His to the fibres of the ventricle, giving first auricular systole and one-tenth of a second later ventricular systole.

Until later years we knew but little of the way any of the chambers of the heart were working excepting the left ventricle, and that mainly from the study of the radial pulse. Now, however, thanks to the possession of the polygraph and electrocardiograph, we are able to study the action of the right side of the heart as well as the left, and record their respective activities as permanent tracings. With the polygraph, to which I intend to refer almost exclusively in this paper, that is achieved by studying the waves in the jugular bulb synchronously recorded with those of the carotid and radial pulse or with the apex-beat. The jugular bulb, as you are aware, is situated behind the gap between the two heads of insertion of the sterno-mastoid muscle-the clavicular and the sternal-and it is really in direct continuity with the cavity of the right auricle. It is, indeed, a portion of that great auriculo-venous reservoir which is separated from the veins of the head and neck by the valves at the upper limit of the bulb and includes the liver and inferior vena caval system in the abdomen.

Let me now direct your attention in the accompanying composite diagram (Fig. 1) to the features of the normal radial pulse curve so well known to you all, and in doing so I may say that it forms a convenient standard in the analysis of jugular and other tracings as I shall shortly explain. A line drawn from the beginning of the upstroke marks the opening of the aortic valves; a second drawn at the dicrotic notch marks the closure of those valves; thus the space between the two lines corresponds with the time during which blood is flowing from the left ventricle into the aorta. This interval is often called the pulse, or "sphygmic" period.

If now you look at the curve of the pulse in the carotid artery you will see that it is similar in form to the radial curve, but that it differs in that its time relation to the ventricular systole is $1 / 10$ th sec. earlier, the wave taking that time to travel from the point of origin of the carotid artery to the wrist.

Look next at this curve of the apex beat, which, you will remember, is not a pressure curve like the others, but a representation of the movement of the chest wall transmitted to it by the movement of the ventricle. The picture is, however, not unlike the carotid or radial pulse curve, but the upstroke begins 1/10th sec. before the carotid upstroke. The aortic valves, you will recognise, are open during the crest of the wave alone; during the upstroke the ventricle is contracting so as to get up sufficient pressure to open the aortic valves. This interval of $1 / 10$ th sec. is known as the "presphygmic period" during which, as I have said, the ventricle is contracting without producing any impression on the blood in the arteries. You will notice, moreover, that before the main upstroke there is a small rounded wave; this is dne to the distension of the ventricle by the blood pumped into it during the auricular systole, and it is known as the auricular wave of the apex curve.

Now let me direct attention to the normal renous pulse curve. If you look at the lower part of the neck where the skin covers the space between the two heads of attachment of the sterno-mastoid muscle, to the sternum and clavicle respectively, you will see in most healthy people, at any rate when recumbent, the venous pulsation referred to, a double flicker for each heart beat. What does it mean? 'The tracing of this movement shows first a rise owing to contraction of the auricle, called therefore the auricular or " $a$ wave" of the venous pulse curve; then comes a fall as the blood passes from the auricle into the ventricle and from the jugular bulb into the auricle. This fall is interrupted, however, by a second rise synchronous with the pulse in the carotid, and probably largely due to the impact of the carotid expansion on the contignous jugular bulb, and is consequently called the carotic or " $e$ wave" of the venous pulse curve. The diastolic fall then continues. A few moments ago I said a double flicker could be seen at the root of the neck for each heart beat, but the two flickerings are not due to the $a$ and $o$ waves - these occur so close together that they cannot be detected separately by the human eye; the second flicker is due to a third wave now to be mentioned. During the ventricular systole the auriculo-ventricular valves are of course closed, and the blood continuing to pour into the auricle from the great veins accumulates in the auricle and jugular bulb and gives rise to the wave named the ventricular or " $~ v$ " wave" of the venous pulse curve, which is really, as you see, a stasis wave. There are other probable contributory causes of the $v$ wave, but I do not intend now to discuss them. With the end of ventricular systole, the pressure in the ventricle and auricle being about the same, the auriculo-ventricular valve opens, and the blood being no longer dammed back in the auricle, the rise of the $v$ wave is followed by its fall. Blood continues to pour continuously from the veins, during what is known as the period of joint diastole, fills ventricle and auricle, and the curve rises slightly and evenly until the pressure in auricle and ventricle is the same, when the auricle again contracts to give the next positive ware, the " $a$ wave" of the succeeding cycle.

Now let me show you how tracings of the jugular pulse are analysed. (Fig. 2.) The first point to make out is, Which is the wave synchronous with the carotid pulse?-in other words, our landmark is the $c$ wave. We know that the pulse appears in the carotid 1/10th sec. before it appears in the radial. If, then, we measure the space on the time record 1/10th sec., or half of one of the divisions being fifth. of a second, and transfer this so as immediately to precede the beginning of the radial upstroke, this will give us the time on the radial tracing at which the beginning of the carotid upstroke occurs. We next measure from this point to the ordinate, or mark of the radial lever when at rest before the tracing began, or after it is ended, and transfer this measurement from the jugular ordinate along the jugular tracing, and that will mark the beginning of the $c$ wave. Having got the $c$ wave, and knowing that the time interval between the beginning of the auricular contraction and the appearance of the carotid pulse is $1 / 5$ th sec., we measure the space of one division of the time-marker back from the beginning of the $c$ wave, and that will give the beginning of the $a$ wave. The $v$ wave is found by measuring the distance from the bottom of the dicrotic notch to the ordinate and transferring the measurement to the jugular curve; this is called the sphygmic period, and it ends at the apex of the $v$ wave as in the tracings displayed.

That, then, is a normal venous pulse curve with a definite auricular $a$ wave, and it is called the aurioular form of venous pulse (Fig. 2). It is thus called because there is another form, the ventrioular form of venous pulse, in which there is no $a$ wave. The auricular form occurs, as I have said, in health and also in all forms of heart disease, except one. In that condition of the heart the auricle is distended or virtually paralysed, and acts merely as a reservoir just as the jugular bulb does. Originating no efficient contraction there is as a natural consequence no sign of an $a$ wave. I show you an example of the ventrioular form of renous pulse. (Fig. 3.)

It is sometimes possible to get tracings in the same patient of the passage of the auricular form into the ventricular form of venous pulse, and in the $a c v$ stage, if it be a case of mitral stenosis, there is a presystolic murmur 
with a crescendo accent; in the $0 v$ stage-that is, when the $a$ wave is absent - there is no presystolic murmur for the reason that there is no contraction of the auricle taking place, but there may be a diastolic murmur which is distinguished by its being diminuendo in accent.

I now purpose, in the second part of my paper, to consider certain typical irregularities of the pulse, the significance of which I may say can hardly be duly appreciated without the study of the action of the right side of the heart by means of the venous pulse in conjunction with the study of the action of the left side of the heart by means of the pulse in the systemic arteries. I intend also to briefly refer to the value in prognosis and treatment that such a study possesses.

Although I shall incidentally say something about irregularities in the rate of the pulse it is to the irregularities in rhythm - the true arrhythmias - that I wish especially to refer. Allow me to enumerate some of them. They are (1) a youthful irregularity known as sinus arrhythmia; (2) an irregularity more characteristic of the aged, known as premature contraction of auricle or ventricle, or otherwise, as "extra-systole"; (3) a complete irregularity of the pulse, the pulsus perpetuus irregularis characteristic of the condition known as auricular fibrillation; (4) the alternating pulse, first a relatively big and then a relatively small beat in recurring succession known as "pulsus alternans"; and lastly (5) an infrequent pulse, or pulse with lengthened pulse periods indicating partial or complete heart-block, and due to failure in or interference with the conducting power of the bundle of His.

First, then, as to the irregularity known as sinus arrhythmia. You know that the sinus venosus is normally the most excitable part of the heart, and that the sinoauricular-node is, indeed, the pace-maker of the heart; when nervous impulses transmitted through the vagus act in an unusual way the pace may vary, and the result is an irregularity of time, but not of force. You remember that Czermak, who had a cartilaginous tumour in his neck, could produce slowing of his heart by pressing on the nodule so as to stimulate his vagus ; also that "standstill" of the heart is easily produced in animals by experimental stimulation of the vagus ; further, that in children and nervous individuals a rhythmical slowing of the heart is sometimes met with coinciding with the respiratory phases of expiration and inspiration, a slowing which is attributed to reflex vagal stimulation. A similar slowing is a not unusual occurrence during the act of swallowing, and it is a corresponding alteration in rate which is known as this neurogenic irregularity or sinus arrhythmia. The slow beats may occur with inspiration and the rapid beats with expiration, or conversely. I show tracings of the condition (Fig. 4), and you will see that the force of the heart beats remain the same, but the length of the diastolic pauses varies.

It is not infrequent to find this variation occurring in association with emotional changes, particularly, perhaps, apprehension or anxiety. Such an irregularity, which more often than not is seen in the earlier periods of life, is easily recognised on feeling the pulse by getting the subject to breathe deeply or to make more or less vigorous muscular exertion, when it vanishes. It is also generally abolished by the administration of belladonna, or in a few minutes by the hypodermic injection of atropine. Venous tracings show that the whole heart participates in the time alteration, inasmuch as the auricular beat keeps time with the ventricular beat, as you see in the tracing. In children, at any rate, the slowing is sometimes accompanied with subjective sensations of giddiness or faintness which may cause a good deal of unnecessary alarm to parents and friends. The condition has, indeed, no serious pathological significance and, in fact, when it occurs, as it often does, after an acute illness or pyrexial attack it is rather a good sign than a bad one, for as a matter of experience it is known that it does not appear if the heart's contractility is materially impaired. It is almost invariable in the healthy dog, and is immediately abolished by section of the vagus, as it is by paralysis of the vagus with atropine in the human subject. It affords no inclication for treatment and none is required. So mucb for what may be called the "youthful irregularity " of the pulse.

The second form of irregularity to which I shall refer is also of no patholocical importance, in the majority of instances at any rate, and although it occurs at any period of life it may fairly be called the "irregularity of the aged." It is known as "extra-systole" and is due to a premature contraction in ventricle or auricle. (Fig. 5.) It often alarms the subjects very much because they are conscious of the irregularity. After a period of normal and regular pulse-beats a small pulse-beat occurs earlier than it should, and then in order to catch up the normal rhythm a long pause occurs. During this long pause the heart accumulates an abnormal supply of contractile energy, and the succeeding beat is larger than normal, as you will see in the tracings. It is the pause followed by the big beat that arrests the patient's consciousness and gives rise to the not unusual alarm. It is easily recognised on auscultation by hearing the first and second sounds sooner than ordinary, of feeble sound value, and succeeded by a long pause. Often, of course, there are no subjective sensations, but often, also, the patient may feel a momentary giddiness and a sensation described as if the heart had stopped or rolled over, followed by a thump. In many cases it has no prognostic significance, or, expressed in other ways, extra systoles may be present in cases in which from any other evidence there is no ground for assuming an unsoundness of the heart-muscle.

In the third place I ask your attention to an arrhythmia in which the irregularity of the pulse is complete, no two waves being alike-big and little, short and long being intermixed without apparently any rhyme or reason. It is the pulsus perpetuus irregularis, or what in the older days was called the "mitral pulse." This pulse, of which I show tracings (Fig. 6), as you know and see, is not only very irregular, but usually also very rapid and small. In an exaggerated phase it has been known as delirinm cordis. I may say that over 50 per cent. of all irregularities of the pulse are of this type. It is only comparatively recently that the real significance of the old-time "mitral pulse" has been recognised. It has been shown conclusively that it is due, as you know, to irregular and multitudinous stimuli originating in the auricle, some alone of which pass to the ventricle to be represented in the arterial pulse wave. The auricle is, in fact, virtually paralysed, acting merely as a receiving chamber, but on inspection in the lower animals its walls may be seen in a condition of endless tremor that has been compared to the fibrillary tremor of the tongue in bulbar paralysis, and hence called auricular fibrillation, and in the human subject it may be found either with or without valvular lesions, in cardio-sclerosis or typically in mitral stenosis.

When it is present continuously, or during a paroxysm merely, the crescendo presystolic murmur of mitral stenosis, as I have already stated, is in abeyance, for there is no auricular contraction to cause it, correspondingly the venous tracing shows no $a$ wave; there is present the ventricular form of venous pulse. (See Fig. 3.) But almost invariably both in the venous pulse curve during diastole of the ventricle and in the electrocardiogram there are numerous small waves - the so-called fibrillation waves-which are taken to be objective evidence of the numerous ineffective movements of the auricular wall. Although there is no longer a presystolic murmur, rough, crescendo, and running up to the accent of the first sound, there is often, as I have also already stated, a diastolic murmur diminuendo in character and separated from the first sound by a distinct interval.

Auricular fibrillation is easily produced in animals by faradic stimulation, but it means in man a serious damage to the muscular wall of the auricle. It is, however, a hopeful sign, in the non-degenerative cases at any rate, in so far that digitalis and its congeners are almost always successful in obviating its bad results. The rapid, irregular pulse under the action of digitalis may in the rheumatic cases be counted on to become slow and regular (see Fig. 6, tracings 2 and 3 ), and the patient makes a good recovery -a recovery, however, which is often only maintained while the digitalis action is kept up. The suggestion is that digitalis produces a condition of partial heart-block in the bundle of His whereby a multitude of irritating impulses are prevented from passing to the ventricle, and hence it has time to rest and gain strength. In such patients digitalis, or a drug of its group, should be given more or less continuously throughout life in a dose the optimum size of which is a matter of investigation for each individual patient.

A fourth irregularity is that known as the alternating 
FIG. 1.

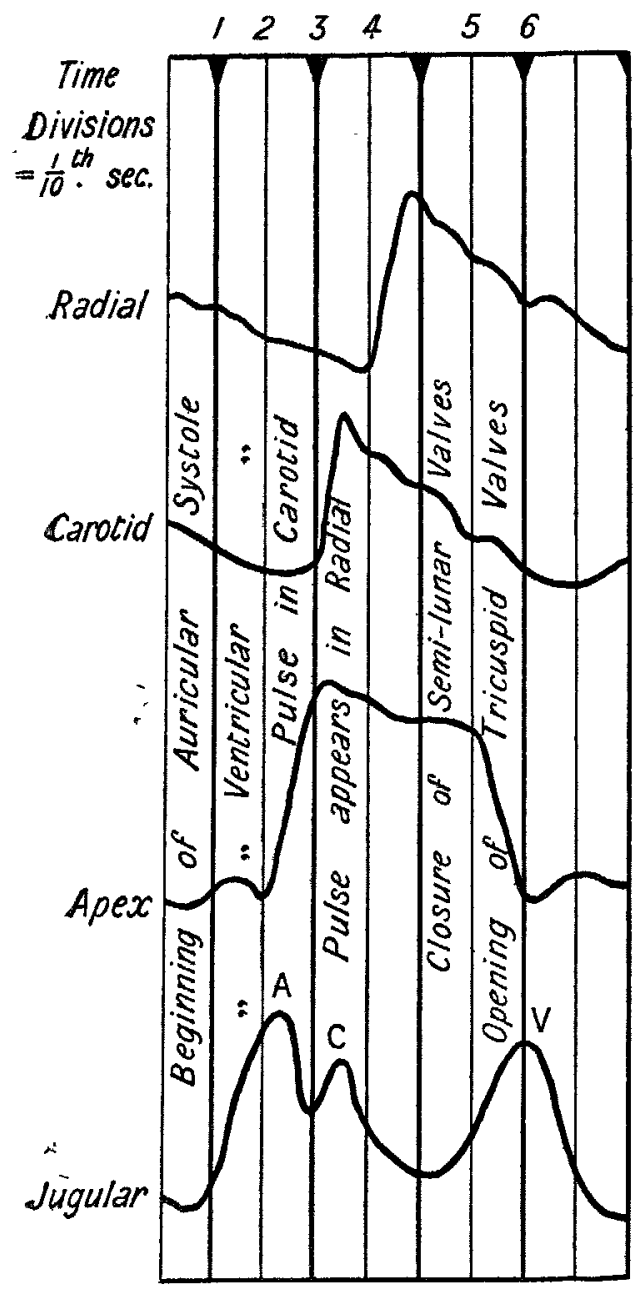

Composite drawing of curves of apex beat, and radial, carotid, and jugular pulses.

FIG. 2.

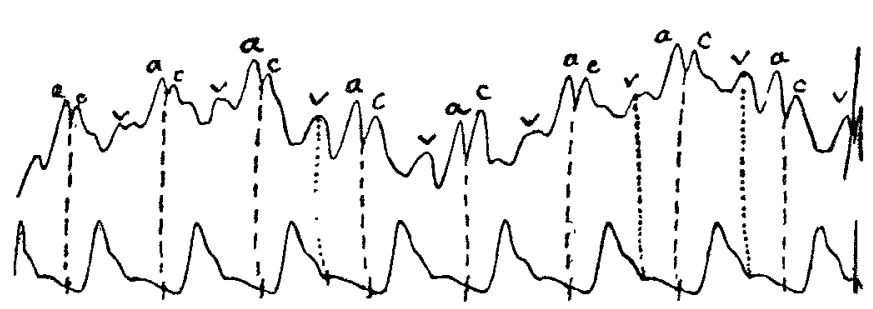

Tracing to illustrate the analysis of the normal jugular pulse. $A$, Wave due to auricular systole; $\mathbf{c}$, Wave due to carotid impact. $\nabla$, Stasis wave An example of the "auricular form " of venouspulse to compare with Fig. 3 .

FIG. 3.

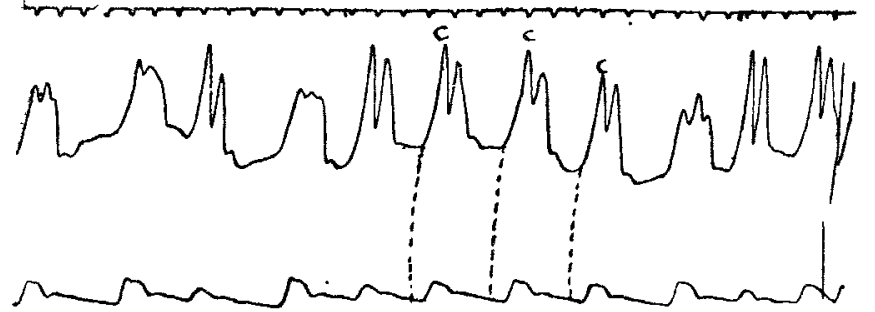

Ventrieular form of venous pulse to compare with the above. Showing absence of any \& wave and complete irregularity of the radial pulse. (From a case of auricular fibrillation.)
Fig. 5.

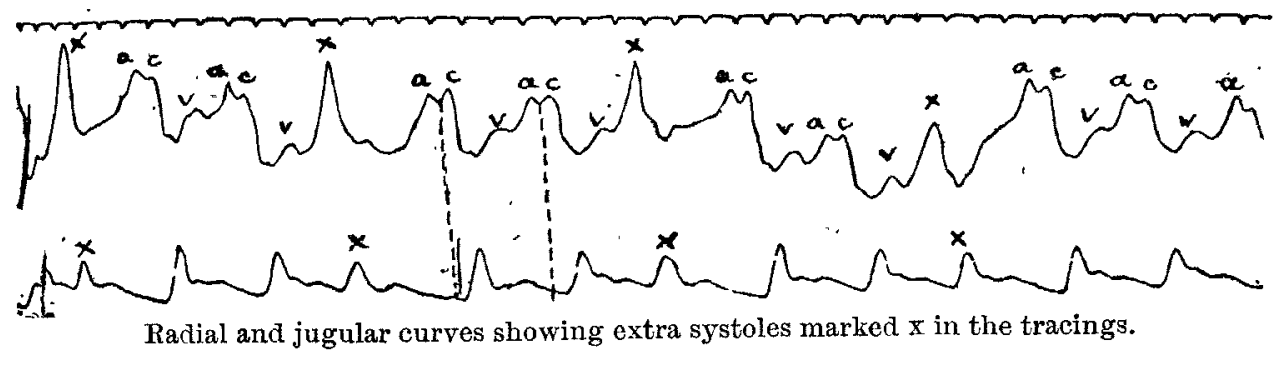

FIG. 6.

(1) Mnghromon

(2)

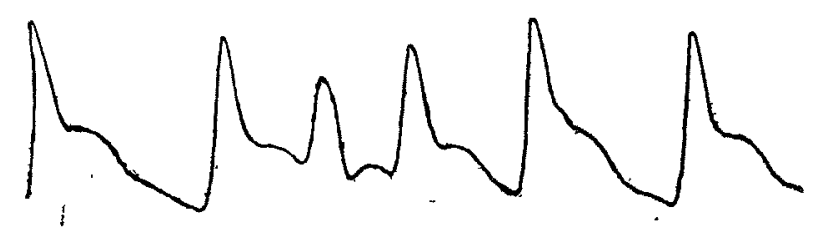

(3)

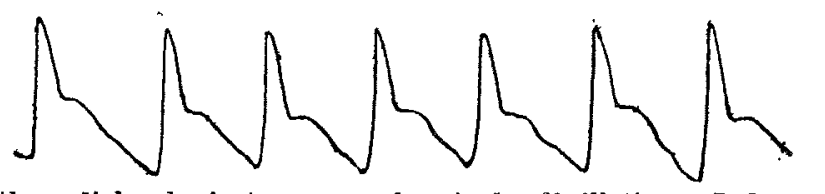

Tracings of the radial pulse in two cases of auricular fibrillation. Pulsus perpetuus irregularis: (1) from a case of rheumatic mitral stenosis; (2) from a case without valvular lesion ; (3) from the same case (2) after treatment with digitalis.

FIG. 7.

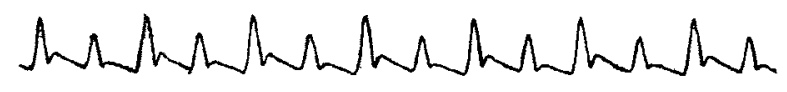

MMMMMMMMMMM

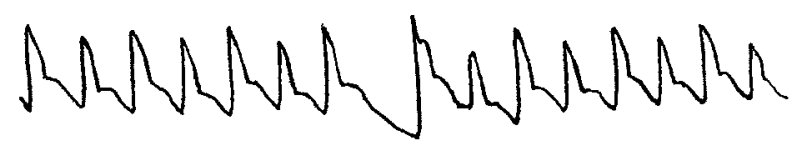

Tracings of the radial pulse from three patients with "pulsus alternans." In the third the alt

FIG. 8.

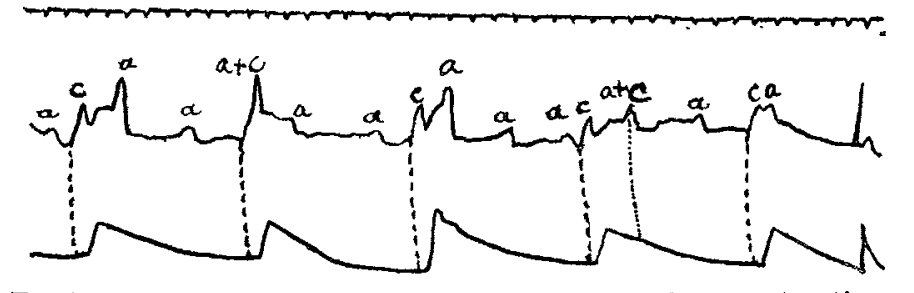

Tracings showing complete heart block. Two or three contractions of the auricle (A) to one beat of the radial pulse.

FIG. 4.

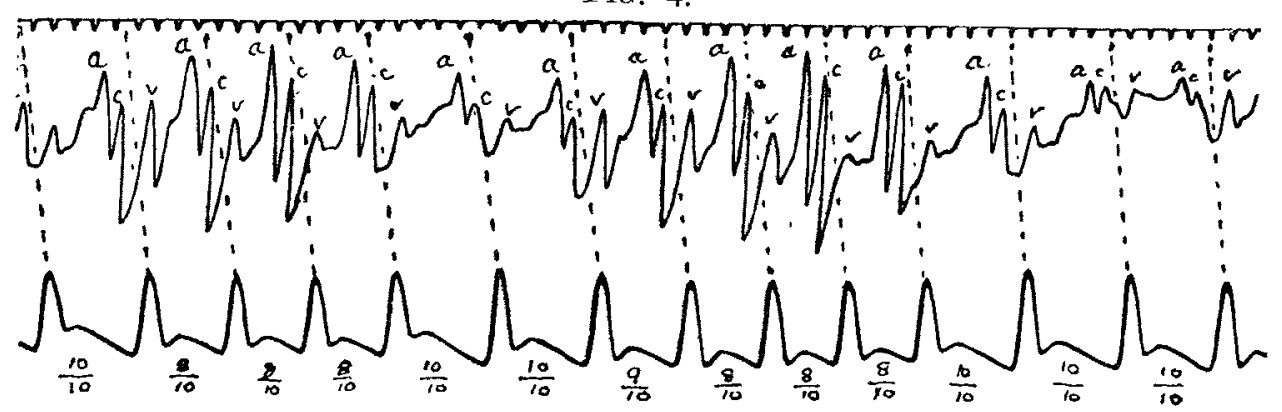

Radial and jugular curves from an instance of sinus arrhythmia; pulse periods, altering with respiration, marked in $1,10 t h$ sec., and varying from 10,10 to $8 / 10$ ths. 
pulse or pulsus alternans. It consists of a regular alternation of large and small beats, with, however, an even rate in respect of time. (See Fig. 7.) In the lower animals it is seen in dying hearts, and in the human subject it is of the gravest possible significance. It means a serious exhaustion of the heart's contractility, and in persons after middle life, at any rate, death usually follows within two years after it has been recognised. Similarly when it is found to have developed in the course of an acute inflammatory illness, as pericarditis, myocarditis, pneumonia, or septic infections, it adds very materially to the gravity of the prognosis.

Among other irregularities to which I should like to refer one is really an irregularity in time. It is the infrequent pulse due to some impairment in the conducting power of the bundle of His, giving rise to what is known as the condition of heart-block. Lesser degrees of this phenomenon may be seen as the result of the action of digitalis and after influenza and other infective diseases, but in its extreme form it constitutes a part of what is known as the Stokes-Adams syndrome, (See Fig. 8.) A patient with this condition, whose normal pulse-rate is, say, 70, is suddenly found to have a rate of only 30 , and there may be fainting attacks or even epileptiform convulsions concurrently. The jugular tracings or electrocardiograms show that the auricle may be beating twice to the ventricle once, as in the curve I show you-that is, every alternate auricular contraction is blocked in the bundle, or only one of every three may get through. In a necropsy I saw lately this blocking was associated with numerous small gummata scattered throughout the myocardium; in other cases a rheumatic nodule may be the effective pathological canse of the condition.

Harley-street, W.

\section{THE RELATION OF IRON TO AN EMIA IN INFANCY AND CHILDHOOD;}

ALSO SHOWING WHAT A LARGE AMOUNT OF IRON THERE IS STORED UP IN THE FOETAL IIVER AT BIRTH.

\section{By HUGH T. ASHBY, B.A., M.B., B.C. Самв., M.R.C.P. LOND.}

ASSISTANT PHYSICIAN TO THE SALFORD ROYAL HOSPITAL.

Is studying anæmia the part played by iron in the blood, in the body, and in the food must be taken into account, and I will try to show what a great part iron plays in the body of the unborn and of infants.

Iron is the great oxygen-carrier both in the earth's crust and in the bodies of animals. It exists in the earth as ferrous and ferric oxides. The former is a strong base and forms neutral salts with the acids, e.g., ferrous silicates, which when decomposed by atmospheric carbonic oxide yield ferrous carbonate. This latter is soluble in water containing carbonic oxide, and is distributed all over the earth. As soon as it comes into contact with atmospheric air it is oxidised to ferric oxide, and the carbonic oxide is set free and returned to the atmosphere. The ferric oxide, when it comes into contact with decomposing organic matter, is reduced, and ferrous carbonate is again formed and carried off by water until it again comes into contact with air and helps to oxidise vegetable and animal refuse.

Iron is thus an indefatigable oxidising agent; it plays the same part in an organism as it does in the earth's crust, and is the great oxygen carrier. In the body the iron exists in the state of a complex organic compound, the hæmoglobin, which forms a loose chemical compound. This is the oxyhæmoglobin, which corresponds to ferric oxide in the earth, and the reduced hæmoglobin to the ferrots oxide.

\section{Absorption of Iron.}

The body gets the iron necessary for its needs through the food; the different foods, however, vary a good deal in the amount of iron which they contain. Thus comparing the amount of iron in different foods : beef, 0.02 ; wheat, 0.026 potato, 0.042 ; peas, 0.024 ; yolk of eggs, 0.04 ; milk, human and cow, 0.003 per 100 parts of dried substance. The course of the iron through the tissues can be traced by histological examination of the stained organs. The test stains for iron in the tissues are ammonium sulphide, potassium ferrocyanide with hydrochloric acid, which gives the Prussian blue reaction, and hæmatoxylin. These stains all colour the iron and not the hamoglobin.

Almost the entire amount of iron given in various forms by the mouth appears again in the faces, and but very little in the urine, even though large quantities of iron are given in the food. In pathological conditions it is said, though, that more iron is eliminated in the urine. Bedder and Smidt, ${ }^{-}$by experimenting on fasting men and animals, have shown that only 1.4-1.7 mg. of iron were excreted in the urine, while 6-10 times the amount was excreted in the fæces every day. Although iron plays such an important part in the body, there is only a very small quantity in the body altogether-viz., 2 $\frac{1}{2}-3 \frac{1}{2}$ grm. (40-55 grains). In the alimentary canal iron undergoes certain changes. The inorganic salts are largely turned into ferric chloride in the stomach, but soon a large part of the iron enters into an organic combination with the protein and forms iron albuminate.

If iron be given to an animal, which is subsequently killed, and if the various organs are then stained for iron, the mucous membrane of the stomach and of the greater part of the small intestine shows no colouration, but the epithelium of the duodenum and the upper part of the jejunum is found to contain numerous granules of iron. The granules may be traced to the mesenteric lymph glands, also around the corpuscles of the spleen, and to a less extent in the liver. $^{2}$ If the animal is kept for some days after giving the iron, the reaction in the duodenum, spleen, and mesenteric glands is less intense, while the liver gives much more evidence of containing iron. Thus, if a litter of guinea-pigs are taken and some fed on milk, which contains very little iron, and others fed on milk + iron given artificially, the livers of the latter are found to contain much more iron than the former, which had no extra iron given in the milk. ${ }^{3}$

Iron can be absorbed by other parts of the small intestine other than the duodenum, as has been shown by Socin, who ligatured a piece of the ileum after having introduced into it a large quantity of iron. Within a few hours all the iron had disappeared, showing that the ileum can take up iron as well as the duodenum. After giving iron by the mouth the epithelial cells of the large intestine and cæcum also give a strong reaction. 'This is interpreted to mean that iron is absorbed by the duodenum and the first part of the jejunum and is taken into the spleen. Later on the iron gets to the liver, where it rests for a time, to be eventually taken up by the blood again and excreted into the large intestine and cæcum. The iron does not escape by the bile, as the composition of the bile is not altered by giving iron to the body.

The liver is the organ that has most to do with the storage and with the metabolism of iron. The liver in intrauterine life receives a very good blood-supply by means of the branches of the umbilical vein carrying arterial blood from the placenta. At birth the liver forms from 4-5 per cent. of the body weight, which is twice the corresponding weight in the adult ( $2 \frac{1}{2}$ per cent. of the body weight). It seems that the liver performs a similar storage function with regard to iron as it does with fats and carbohydrates. When the iron is needed it is given $\mathrm{up}$ by the liver into the blood again, and used to make new hæmoglobin and red blood corpuscles. The absorption of iron from the intestine is, however, regulated by the demand, so that rarely are larger amounts than normal found in the liver, which fact my analysis bears out. In some diseases, such as pernicious anæmia, hypertrophic cirrhosis of the liver, there is a large amount of iron found in the liver which has been derived from the blood.

The liver has also other functions in connexion with this iron. Together with spleen it separates the iron from effete iron-containing pigment which it stores in the form of a loose compound. The liver also transforms this iron into an organic compound, ferratin, which is ready for assimilation by young red blood cells, and is given out as it is required to make new hæmoglobin.

When iron is given to a patient much the greater quantity is excreted again in the fæces, but at times it appears as if large quantities are kept in the body. ${ }^{\overline{5}}$ Thus a patient

1 Das Sekret in Resorp in Dünndarm, Zeitschrift für Biologie, 1892

2 Eisenresorptum, Archiv für die gesammte Physiologie des Menschen 2 Eisenresorptum, Archiv für die gesammte Physiologie

4 In welcher Form wird das Eisen resorbiert, Zeitschrift für die angewandte Chemie, 1891 . 